\title{
THE EFFECT OF PARITY ON DECIDUAL, PLACENTAL AND FETAL WEIGHT IN THE MOUSE
}

\author{
C. M. HETHERINGTON* \\ Institute of Animal Genetics, Edinburgh
}

(Received 9th August 1971, accepted 18th August 1971)

Summary. In random-bred $Q$ mice, decidual weight on the 7 th day of pregnancy and placental and fetal weight on the 18th day of pregnancy were compared in nulliparous and uniparous females and those which had undergone a previous pseudopregnancy with or without induction of decidual tissue by arachis oil.

The effect of parity was to increase maternal weight and placental weight but to decrease fetal weight. There was no effect on decidual weight. Pseudopregnancy with or without the induction of deciduomata failed to mimic the effects of parity on fetal weight and placental weight.

Placental weight and birth weight increase with parity in a number of species (McKeown \& Record, 1953, McCarthy, 1965, Jones, 1968; Warburton \& Naylor, 1971) while fetal weight at a given time of gestation may increase (McKeown \& Record, 1953) or decrease (McCarthy, 1965). The way in which parity affects these parameters is not known. It has been suggested (Jones, 1968; Warburton \& Naylor, 1971) that immunological factors may be responsible. It is equally possible that changes in the uterine environment which have no immunological basis could be responsible for the effects associated with parity.

Decidual, placental and fetal weight were studied in mice that had undergone a previous pregnancy or pseudopregnancy. During pseudopregnancy, one group of mice received intrauterine injections of arachis oil to induce the formation of decidual tissue (Finn \& Hinchliffe, 1964) which is known to be similar both histologically and histochemically to that induced by an implanting blastocyst (Finn \& Hinchcliffe, 1964, 1965).

Nulliparous, random-bred $Q$ mice, 6 weeks old, were allocated to four groups. The females of Group I were mated to proven fertile $Q$ males and were allowed to rear their litters for 3 weeks. Pseudopregnancy was induced in the mice of Groups II and III by mating with vasectomized $Q$ males. On the 4th day of pregnancy, both uterine horns of the mice of Group II were injected with $0.03 \mathrm{ml}$ arachis oil in order to induce massive deciduomata (Finn \& Hinchcliffe, 1964). Group III was left untreated and the mice of Group IV were kept unmated. Subsequently, all mice were weighed and mated at 12 weeks of age to proven males.

Mice of each group were killed on either the 7th or 18th day of pregnancy.

* Present address: Clinical Research Centre, Watford Road, Harrow, Middlesex. 
Decidual tissue was dissected from the uteri of those killed on the 7 th day and the tissues from each uterus were weighed together. The mean decidual weight of each implant was calculated. No attempt was made to remove the conceptus from the decidual tissue. Fetuses and placentae from mice killed on the 18th day were weighed individually. The mean fetal weight and the mean placental weight for each female was calculated.

The total number of decidual swellings on the 7th day and the sum of early, middle and late deaths and live fetuses on the 18th day (McLaren \& Michie, 1959) were called the implant number. In calculations of the regressions of placental weight and fetal weight on litter size, the latter was taken as the implant number minus the number of early deaths, as shown to be appropriate by Healy, McLaren \& Michie (1960).

The data obtained in this study are presented in Table 1 . Neither parity nor pseudopregnancy affected decidual weight $(F=1.50$, d.f. $=3$ and 81$)$, though the mean decidual weight in mice in which massive deciduomata were induced (Group II) was significantly heavier than the mean decidual weight obtained from pooling the data of the other three groups $(P=0 \cdot 05)$.

Regression analysis indicated that none of the treatments modified the effect of litter size on placental weight $(F=1 \cdot 28$, d.f. $=1$ and 75).

The mean placental weights, adjusted by regression analysis for variations in litter size, using the pooled within-group regression coefficient, showed that the placentae of uniparous mice (Group I) were heavier than those of both nulliparous mice (Group IV, $P<0.05$ ) and the pseudopregnant groups (Groups II and III, $P<0.05)$. Placental weights in Groups II and III tended to be greater than those of nulliparous mice (Group IV) but even when the data of Groups II and III were pooled, this difference was not significant $(F=1.91$, d.f. $=1$ and 69).

The regressions of fetal weight on litter size differed significantly between groups making impossible any regression analysis of the differences between means. It is apparent, however, that the fetal weights of uniparous females (Group I) were the lowest, while the differences between the other three groups were small.

The body weight of uniparous females was significantly greater at 12 weeks of age than that of nulliparous Group IV mice $(P<0.01)$. There was no significant difference between the body weight of nulliparous mice and those which had undergone a pseudopregnancy (Groups II and III).

The data for similarly treated mice were pooled to study total implant number. The total number of implants in the nulliparous mice and those of Group II $(10.6 \pm 0.4,10.4 \pm 0.5)$ were both significantly less than those of Groups I and III $(12 \cdot 0 \pm 0 \cdot 6,12 \cdot 0 \pm 0 \cdot 4 ; P<0 \cdot 01)$.

Parity but not pseudopregnancy resulted in an increase in female body weight compared to that of nulliparous mice of the same age. Both parity and pseudopregnancy without induction of deciduomata increased implantation number, but when massive deciduomata were induced during pseudopregnancy, the implantation number did not differ significantly from that of nulliparous mice. If a similar ovulation rate is assumed for the mice of Groups II and III, it may be concluded that the ability of the uterus to support implantation is reduced 


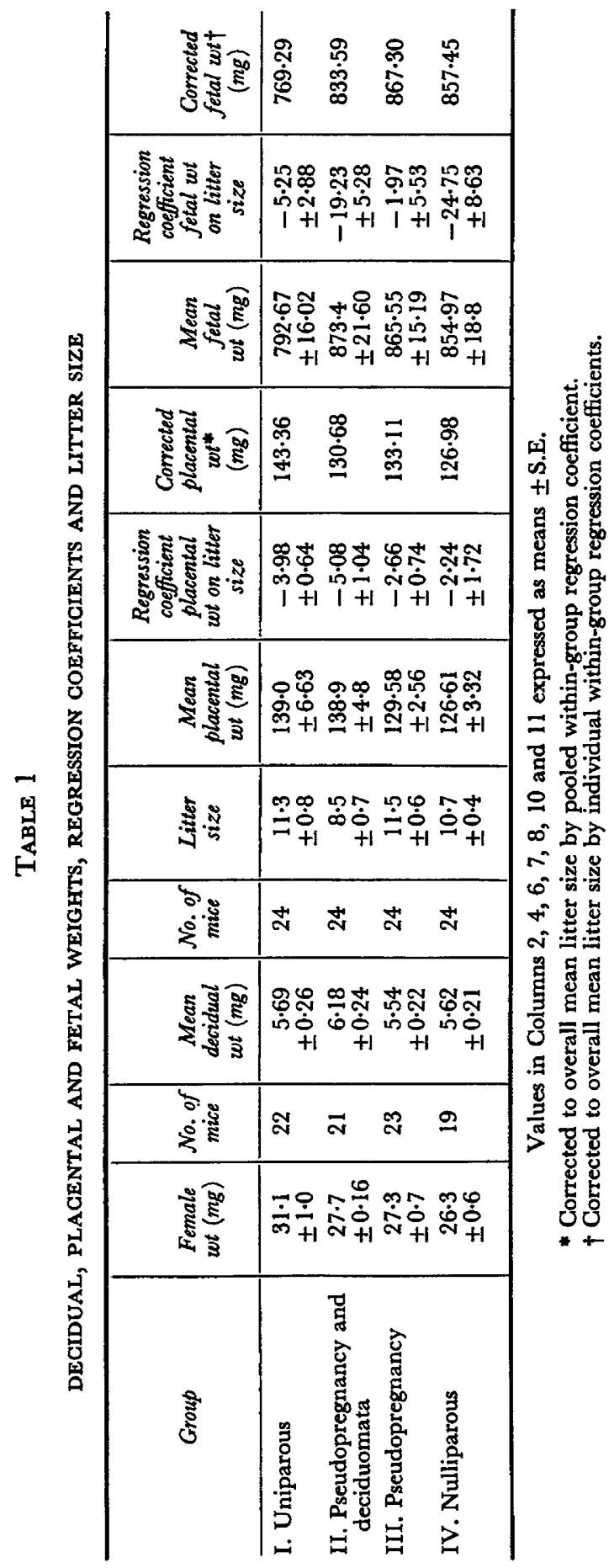


in mice in which deciduomata have been induced. After the injection of $0.03 \mathrm{ml}$ arachis oil per horn into the pseudopregnant uterus, the decidual cell reaction generally involves almost the whole of both uterine horns. The effect of the induction of such deciduomata appears to be twofold. First, the probability of successful implantation is reduced. This may be due to certain areas of the uterus having had insufficient time, or being unable, to recover from the induction of deciduoma. Second, if implantation is successful, then the decidual response is increased. Parity had no similar effect. As implantation in the second pregnancy is unlikely to occur at the same uterine site as in the first pregnancy, this may indicate that the increased uterine responsiveness is localized in the areas where decidual tissue has previously been induced.

Alternatively, parity and the induction of deciduomata may not be directly analogous. Uterine ability to respond to the decidual stimulus may increase in both instances. The uterine environment may be modified, however, so that blastocysts in uniparous mice are less able to elicit the decidual cell reaction than are similar blastocysts in the uteri of mice which have undergone a pseudopregnancy with artificial decidualization.

There was no evidence that pseudopregnancy, with or without the induction of decidual tissue, had any effect similar to that of pregnancy on subsequent placental or fetal weight.

The placentae of uniparous mice were significantly heavier than those of nulliparous mice while the fetuses were lighter. Placental weight in the mouse decreases towards the end of pregnancy (McLaren, 1965) and parturition occurs when fetal weight reaches a critical size (McLaren, 1967). The lighter fetuses and heavier placentae may reflect a longer gestation period in uniparous $\mathrm{Q}$ mice. Gestation period increases with parity in a number of species (McKeown $\&$ Record, 1954). The respective gestation periods in uniparous and nulliparous $Q$ mice mated at 12 weeks of age were found to be $19 \cdot 13 \pm 0.04$ and 19.21 \pm 0.09 days. It is unlikely that this difference in duration can explain the differences in placental weight.

Since the strain of mice used in this study was random-bred, and uniparous females were not mated to the same sire in both pregnancies, changes in the mother's immunological status with respect to paternal antigens are unlikely to provide an explanation for these parity dependent changes. Changes in immunological status with respect to tissue-specific embryonic antigens, however, cannot be ruled out.

I am grateful to the Medical Research Council for financial support and to the Ford Foundation for equipment. I should also like to thank Dr A. McLaren for her comments during the course of the work.

\section{REFERENCES}

Fivn, G. A. \& Hinchliffe, J. R. (1964) Reaction of the mouse uterus during implantation and deciduoma formation as demonstrated by changes in the distribution of alkaline phosphatase. 7. Reprod. Fert. 8, 331.

FinN, G. A. \& Hinchliffe, J. R. (1965) Histological and histochemical analysis of the formation of implantation chambers in the mouse uterus. F. Reprod. Fert. 9, 301. 
Healy, M. J. R., Mclaren, A. \& Michie, D. (1960) Foetal growth in the mouse. Proc. R. Soc. B, $153,367$.

JoNEs, W. R. (1968) Immunological factors in human placentation. Nature, Lond. 218, 480.

MaGarthy, J. C. (1965) Genetic and environmental control of foetal and placental growth in the mouse. Anim. Prod. 7, 347.

McKeown, T. \& Recond, R. G. (1953) The influence of placental size on foetal growth according to sex and order of birth. F. Endocr. 10, 73.

McKeown, T. \& Record, R. G. (1954) Influence of maternal size and parity on onset of labour in multiple pregnancy in man. F. Endocr. 11, 160.

McLaren, A. (1965) Placental weight loss in late pregnancy. F. Reprod. Fert. 9, 343.

McLaren, A. (1967) Effects of foetal mass on gestation period in mice. F. Reprod. Fert. 13, 349.

McLaren, A. \& Michie, D. (1959) Superpregnancy in the mouse. 1. Implantation and foetal mortality after induced superovulation in females of various ages. F. exp. Biol. 36, 281.

Warburton, D. \& NaYlor, A. F. (1971) The effect of parity on placental weight and birth weight: an immunological phenomenon? A report on the collaborative study of cerebral palsy. Am. 7 . hum. Genet. 23, 41. 